\title{
Gelatine Microspheres Support Direct Intramyocardial Delivery of Induced Pluripotent Stem Cell-Derived Cardiomyocytes
}

Raja Ghazanfar Ali Sahito', Carlos O Heras-Bautista' ${ }^{1}$, Benjamin Krausgrill², Martina Maass ${ }^{2}$, Sven Baumgartner ${ }^{1,2}$, Jurgen Hescheler ${ }^{1}$, Agapios Sachinidis ${ }^{1}$ and Kurt Pfannkuche ${ }^{1 *}$

${ }^{1}$ Institute of Neurophysiology, University of Cologne, Robert-Koch Str. 39, 50931 Cologne Germany

${ }^{2}$ Department of Internal Medicine III, University of Cologne, Kerpener Str. 62, 50937 Cologne, Germany

\begin{abstract}
Objective: Cardiac cell replacement therapy (cellular cardiomyoplasty) aims at restoring contractile function following cardiac infarction or cardiac myopathy and may add a new option to conventional treatments of cardiac failure in the future. Currently, this approach is hampered by the minor rate of cell engraftment and optimal strategies and routes of cell delivery need to be identified. Delivery of cardiomyocytes immobilized on biodegradable microspheres could support cell transfer.
\end{abstract}

Methods: Murine induced pluripotent stem cell derived cardiomyocytes (iPS-CMs) expressing puromycinacetyltransferase and enhanced green fluorescent protein (eGFP) under control of the Acta-2 promotor were used. Macroporous gelatine microspheres were loaded with single cell suspensions of purified iPS-CMs and transplanted into healthy murine myocardial tissue. Single cell suspensions were transplanted for control. Persisting cells were determined by quantitative real-time PCR with Y-chromosome specific primers and histological analysis.

Results: Upon direct intramyocardial injection of iPS-CMs only $12.3 \pm 4.4 \%$ of injected cells were detectable immediately after injection and this value further declined to $1.3 \pm 0.5 \%$ at $24 \mathrm{~h}$. In contrast delivery of iPS-CMs on microspheres resulted in a persistence of $4.2 \pm 1.2 \%$ at $24 \mathrm{~h}$ ( $\mathrm{p}<0.05$ vs. iPS-CMs only). Histological analysis $24 \mathrm{~h}$ after transplantation revealed the presence of eGFP+ ${ }^{+}$PSS-CMs in the myocardiac tissue. However, one week after cell transfer no iPS-CMs were detectable.

Conclusion: Intramyocardial transfer of iPS-CMs bound to gelatin microspheres enhances cell retention in the early stage after transplantation significantly. However, the total cell loss remains high and long-term cell loss cannot be prevented by this approach. These findings support the conclusion that Anoikis is no major cause of cell loss during experimental cardiomyoplasty.

Keywords: Embryonic stem cells; Induced pluripotent stem cells; Microsphere; Microcarriers; Cardiomyocytes; Cell replacement therapy; Regenerative medicine; Cardiac reconstruction; Cardiomyoplasty

\section{Introduction}

Cardiac cell replacement therapy is considered as a promising option to restore the contractile capacity of cardiac tissue following myocardial infarction or cardiomyopathy (for a review see [1]). Albeit under investigation in different animal models for more than a decade current methods are still more than a few steps away from translation into preclinical trials. The optimal route of cell delivery is one question that is under debate [2]: direct injection of cell preparations into the ventricular wall delivers cells locally into the damaged tissue at the cost of a restricted distribution of transplanted cells. Intracoronary application of the cells appears as an alternative because cells are distributed along the capillary bed. However, there is no evidence that cardiomyocytes or progenitors thereof pass the endothelial lining of the vessels and translocate to the muscular tissue. Moreover, experimental studies point to a risk of thrombogenesis [3].

Direct intramyocardial injection allows for different choices of cell preparation: Cells can be transferred as single cell suspension [4], cell clusters composed of one or multiple cell types [5], cell sheets [5-8], gels in the form of injectable proteins/polymers $[9,10]$ or solid aggregates composed of engineered matrix materials and cells (present study). Application of special suture techniques helps retaining transplanted cells and were successfully applied in a non-human primate model of cardiac regeneration [11]. While delivery of single cell suspensions will promote the spreading of the cells in the tissue cell clusters and aggregates composed of cells and matrix will likely support transplanted cells with an environment promoting cell survival by providing cell-cell and cell-matrix contacts.

Pluripotent stem cells such as embryonic (ES) cells and induced pluripotent stem (iPS) cells can be differentiated into functional cardiomyocytes [12,13] and may therefore serve as a source of transplantable cells. It can be speculated that transplantation of single cell suspensions of such cardiomyocytes does not optimally support their integration for several reasons: First of all injection of the cell suspension will result in a pressure gradient that directs the cell suspension out of the tissue. This effect will be increased when cells are injected into contracting myocardium due to the elevated pressure in the contracted tissue. Transfer of larger particles could help to reduce wash out of the cells. Secondly, the individual cells lack cell-cell and cellmatrix contacts and may be subjected to Anoikis (discussed by Zvibel et al. [14]). Indeed high rates of apoptosis reaching $35 \%$ one day after

*Corresponding author: Kurt Pfannkuche, Center of Physiology and Pathophysiology, Institute of Neurophysiology, University of Cologne, Robert-KochStr. 39, Germany, Tel: 490221478 6940; E-mail: kurt.pfannkuche@uni-koeln.de

Received August 24, 2015; Accepted September 24, 2015; Published September 26, 2015

Citation: Sahito RGA, Heras-Bautista CO, Krausgrill B, Maass M, Baumgartner S, et al. (2015) Gelatine Microspheres Support Direct Intramyocardial Delivery of Induced Pluripotent Stem Cell-Derived Cardiomyocytes. J Stem Cell Res Ther 5: 306. doi:10.4172/2157-7633.1000306

Copyright: (c) 2015 Sahito RGA, et al. This is an open-access article distributed under the terms of the Creative Commons Attribution License, which permits unrestricted use, distribution, and reproduction in any medium, provided the original author and source are credited. 
injection have been observed after intramyocardially transplantation of neonatal rat cardiomyocytes [15].

Generation of microspheres (microcarriers) loaded with cardiomyocytes is one possible strategy to address these problems. Already in 1967 Van Wezel has introduced a technology to employ biomaterial-based microspheres as scaffolds for homogenous cell cultures [16]. Microspheres are generated from cell culturecompatible materials and allow for surface-bound culture of cells in a suspension bioreactor system and were successfully applied to neonatal cardiomyocytes [17]. In our days the concept has been extended towards generation of stem cell-derived cardiomyocytes in settings of microsphere-based suspension cultures $[18,19]$.

Macroporous microspheres composed of gelatine appear suitable for cardiomyocyte culture and have been shown to support cultivation of iPS cell-derived cardiomyocytes (iPS-CMs) previously [18]. In this study we analyze the potential of such microspheres to support intramyocardial delivery of murine ventricular-like iPS-CMs.

\section{Materials and Methods}

\section{Cell culture}

Murine male iPS cells carrying a transgene coding for puromycinacetyltransferase and enhanced green fluorescent protein (eGFP) under control of the Acta2 promoter have been described and carefully characterized in a previous study [20]. Application of a cardiac differentiation protocol and selection by puromycin resulted in a high enrichment of cardiomyocytes mainly exhibiting a ventricular-like phenotype [20]. Undifferentiated cells were maintained on a layer of mitotically inactivated feeder fibroblasts (MEFs). MEFs were obtained from e14.5 embryos of outbred mice at passage 3 . MEFs were mitotically inactivated by incubation with Mitomycin C ( $10 \mathrm{mg} / \mathrm{ml}$, Serva) for 3-4 hrs. iPS cells were cultured on $60 \mathrm{~mm}$ plates covered with $8 \times 10^{5} \mathrm{MEFs}$ at $37^{\circ} \mathrm{C}$ and $5 \% \mathrm{CO}_{2}$ in ES medium, composed of IMDM with Glutamax supplemented with $1 \%$ Penicillin/Streptomycin (100x solution) and $1 \%$ non-essential amino acids (MEM 100x solution) as well as $17 \%$ fetal bovine serum and $1000 \mathrm{U} / \mathrm{ml}$ of LIF (ESGRO, Chemicon). All reagents were purchased from Invitrogen/LifeTechnologies if not stated otherwise. The culture was divided every 2-3 days.

To differentiate iPS cells to iPS-CMs cultures were dissociated ( $0.05 \%$ trypsin/EDTA) to single cells. $2.5 \times 10^{6}$ cells were re-suspended in $12 \mathrm{ml}$ of ES medium with addition of $3 \mathrm{mg} / \mathrm{ml} \mathrm{L}$-Ascorbic-Acid phosphate-Magnesium-Salt-n-Hydrate (Wako Chemicals $\mathrm{GmbH}$, Germany) but without LIF. The suspension was incubated in a nonadhesive plastic dish at $37^{\circ} \mathrm{C}$ and $5 \% \mathrm{CO}_{2}$ with continuous agitation (50 revolutions per minute) on a rocking table inside a cell culture incubator in order to form embryoid bodies (EBs). After two days, EBs were collected in a $15 \mathrm{ml}$ Falcon tube and counted. EBs were distributed at 1000 per plate $(10 \mathrm{~cm})$ in $12 \mathrm{ml}$ ES Medium without LIF and further cultured under continuous agitation. EBs were monitored until spontaneous contractions were observed.

Once beating EBs were found - usually on day 7 or 8 - medium was completely exchanged and supplemented with $8 \mu \mathrm{g} / \mathrm{ml}$ puromycin. Puromycin driven lineage selection was performed till day 15 of differentiation in order to purify CMs; medium was changed every 2 days. Clusters of purified CMs were collected in a $15 \mathrm{ml}$ centrifuge tube and left for $5 \mathrm{~min}$ to collect by gravity. Afterwards, EBs were washed twice with calcium- and magnesium-free PBS, supernatant was removed and $0.5 \mathrm{ml}$ of trypsin/EDTA $(0.05 \%)$ were added to the pellet and transferred to a $3 \mathrm{~cm}$ petri dish containing $2.5 \mathrm{ml}$ of trypsin/EDTA
(0.05\%). Cell clusters were then incubated $\left(37^{\circ} \mathrm{C}\right.$ and $\left.5 \% \mathrm{CO}_{2}\right)$ for 15 min and subsequently monitored under an inverted microscope. If necessary $1 \mathrm{ml}$ of fresh trypsin/EDTA $(0.05 \%)$ was added and the dish was transferred again to the incubator for another $5 \mathrm{~min}$. Afterwards cell suspension was briefly and carefully aspirated repeatedly with a pipette (upper limit 10 times) and dissociation was then stopped by the addition of serum containing medium.

\section{Preparation of microspheres}

Microspheres (Cultisphere-S, Percell Biolytica, Sweden) with a diameter of 130-380 $\mu \mathrm{m}$ were prepared according to manufacturer's instructions. In brief, dry Cultisphere-S microspheres were rehydrated in phosphate buffered saline (PBS, 50ml PBS/g dry microspheres) as described before [9]. Spheres were kept in PBS for 1 hour at room temperature and sterilized for 15 minutes at $121^{\circ} \mathrm{C}$ and $15 \mathrm{psi}$. Later PBS was removed and microspheres were washed once with fresh PBS and twice with Iscove's modified Dulbecco's Medium (IMDM, LifeTechnologies, Germany) by repeated pipetting. Counting of microspheres was performed in a haemocytometer. In order to load microspheres with iPS-CMs $2.0 \times 10^{6}$ iPS-CMs were seeded into a $3 \mathrm{~cm}$ bacteriological dish (non-adhevise) in culture medium containing $17 \%$ FCS together with 200 microspheres on an orbital shaker at $50 \mathrm{rpm}$ for 4 days. Samples were analysed on a Zeiss Axiovert 200 inverted microscope for presence of eGFP fluorescence. Approximately 100 loaded microspheres were resuspended in $20 \mu \mathrm{l}$ for injection. For histological analysis microspheres were stained with CMTPX dye prior to loading.

\section{CMTPX labeling}

CMTPX labeling of microspheres was performed prior to coculture with cells. For labeling 200 microspheres were collected per $3 \mathrm{~cm}$ dish, and CMTPX (Molecular Probes, distributed by LifeTechnologies, Karlsruhe, Germany) was added at a concentration of $5 \mu \mathrm{M}$ in cell culture medium containing 15\% FCS. Samples were incubated for 45 minutes at $37^{\circ} \mathrm{C}$. This protocol is sufficient to label the microspheres with an intense red fluorescence. Following incubation the working solution was replaced with pre-warmed culture medium and incubated for another 30 minutes at $37^{\circ} \mathrm{C}$.

\section{MTT test for cell viability}

$400 \mu \mathrm{l}$ volume of the microsphere suspension were loaded on an individual well of a 24 well plate. In order to prepare a stock solution the MTT (3-[4,5-dimethylthiazol-2-yll-2, 5-diphenyltetrazolium bromide) reagent was dissolved in calcium- and magnesium-free PBS to a final concentration of $5 \mathrm{mg} / \mathrm{ml}$. $40 \mu \mathrm{l}$ of the MTT stock solution were added to each individual well of the 24 -well plate loaded with microspheres. The 24-well plate was incubated at $37^{\circ} \mathrm{C}$ for 45 minutes and analyzed on a conventional phase contrast microscope. Viable cells take up MTT that is cleaved by an enzyme in the respiration chain in the mitochondria generating MTT formazan a dark blue highly visible product.

\section{Surgery and transplantation}

Transplantation protocols were approved by the animal welfare committee according to animal care law of laboratory animals. Adult female syngeneic mice 129 P2 Ola, 6-8 weeks old were used in this study. Surgeries were performed as described in detail before [21]. Cells were injected into the left ventricular wall (close to the apex) of healthy female hearts by two injection of $10 \mu \mathrm{l}$ each. The experimental group received 100 loaded microspheres per heart; the control group received $20 \mu \mathrm{l}$ of a single cell suspension containing $5 \times 10^{5}$ iPS-CMs. 
Counting of microspheres was performed in a haemocytometer. The cell preparation for injection was started no longer than 30 minutes prior to transplantation. In order generate the sample for injection the microsphere suspension was collected into a conical centrifuge tube and microspheres were collected by gravity. No centrifugation of the loaded microspheres was applied. The supernatant was carefully removed as complete as possible. $20 \mu \mathrm{l}$ of fresh culture medium were added. Cells were left on ice until injection.

\section{Sample collection and analysis}

The hearts were harvested immediately ("0min"), after $6 \mathrm{~h}$ and $24 \mathrm{~h}$ following cell transplantation. Samples were stored frozen for realtime PCR at $-20^{\circ} \mathrm{C}$. Cell quantification by real time PCR has been demonstrated before [22,23]. Briefly, genomic DNA was isolated from tissue samples and the number of male transplanted cells in to female recipients was determined with primers specific for a Y-chromosome located gene. In each surgery day one additional aliquot of each samples group was combined with an explanted heart ex-vivo and served as control (Ctrl) to set the $100 \%$ level.

\section{Histology}

Slices were prepared as described before [16]. Organs were isolated and embedded in $4 \%$ low melt agarose (Roth, Germany). The agarose block was glued on a specimen holder and maintained in ice-cold Tyrode solution without calcium (composition in $\mathrm{mmol} / \mathrm{l}$ : $\mathrm{NaCl} 136$, $\mathrm{KCl} 5.4, \mathrm{NaH}_{2} \mathrm{PO}_{4} 0.33, \mathrm{MgCl}_{2}$, glucose 10, hepes 5, 2,3-butanedione monoxime 30; pH 7.4 adjusted with $\mathrm{NaOH}$ ). Short axis heart slices of $150 \mu \mathrm{m}$ thickness were produced with a VT $1000 \mathrm{~S}$ microtome (Leica, Germany) and stored in Tyrode solution with $0.9 \mathrm{mmol} / \mathrm{l}$ calcium. For sectioning samples were fixed in $4 \%$ paraformaldehyde for 2 hours at $4^{\circ} \mathrm{C}$ and transferred into calcium-magnesium free PBS. These fixed samples were embedded in Tissue-Tek O.C.T. (Sakura Finetec Germany $\mathrm{GmbH}$, Germany) and cut into slices of $8 \mu \mathrm{m}$ thickness on a cryotome (Leica). Images were acquired on an Axiovert $200 \mathrm{M}$ microscope (Zeiss, Germany).

\section{Statistical analysis}

All data are presented as mean \pm SEM calculation. Statistical evaluation has been done by InStat ${ }^{\oplus}$, Prism ${ }^{\bullet}$ (both GraphPad Software Inc., USA) and SPSS (SPSS in., USA) using one way ANOVA for unpaired values with correction for multiple comparisons and appropriate post test and student t-test.

\section{Results}

\section{Entrapment of cardiomyocytes into microspheres}

Induced pluripotent stem cells carrying a puromycin-acetyl transferase transgene as well as a coding sequence for eGFP under control of the Acta2 promoter were chosen for this study. Differentiation of pluripotent iPS cells under conditions favorable of cardiac differentiation resulted in the formation of spontaneously contracting embryoid bodies. Puromycin selection was performed as detailed in the materials and methods section and resulted in the generation of a population of $\mathrm{eGFP}^{+}$cells, mainly consisting of purified ventricular myocytes as has been shown in a previous study.

To facilitate intra-myocardial delivery of the purified iPS-CMs gelatin microspheres (Figure 1A) were utilized as a vehicle to entrap iPS-CMs. Microspheres were loaded with iPS-CMs as described in materials and methods. A high degree of cell entrapment was observed already at day 2 post seeding (Figure 1B). However, plenty of iPS-CMs
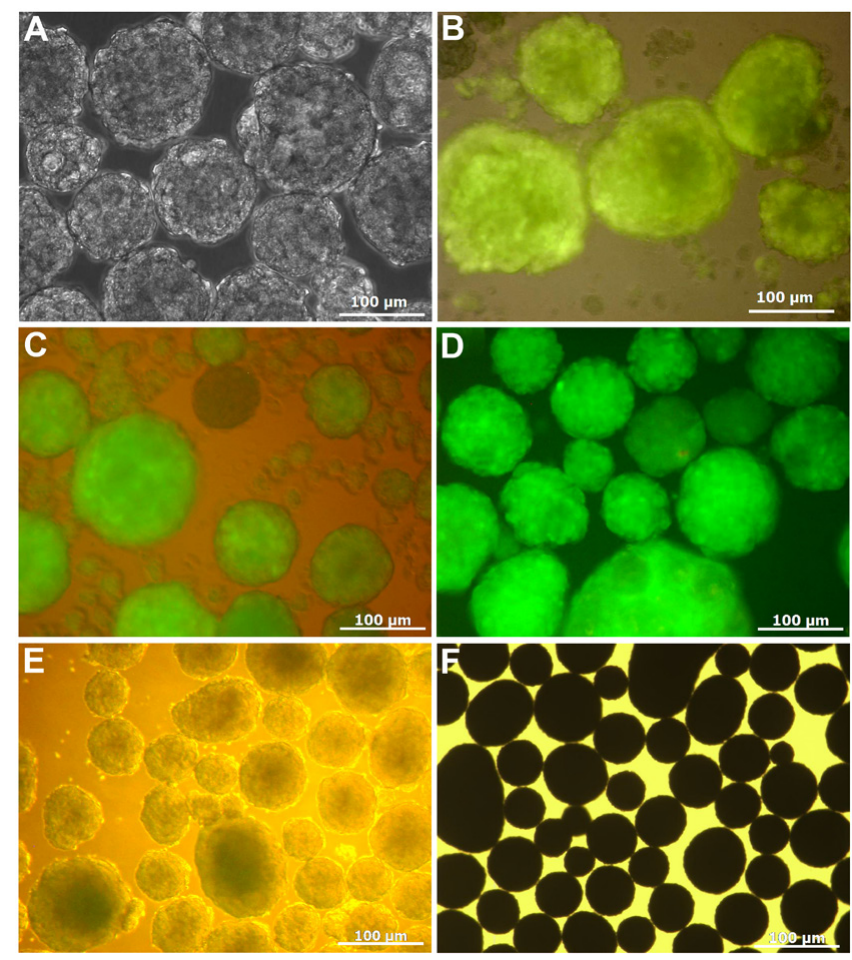

Figure 1: Co-culture of iPS-Acta 2 derived cardiomyocytes on CultipshereS micropsheres. Empty microsphere in culture without cells (A). Coculture of eGFP+ cardiomyocytes with microspheres at day 2 post seeding (B). Coculture of eGFP+ cardiomyocytes with microspheres at day 4 post seeding (C). Manually enriched cell-loaded microsphere expressing eGFP+ at day $5-6$ post seeding $(D, E)$. MTT staining of loaded microspheres at day 8 post seeding $(F)$.

remained freely floating or aggregated in small clusters as indicated by fluorescence microscopy. On day 4 after cell seeding the majority of iPSCMs appeared trapped into Cultisphere-S microspheres (Figure 1C). Hence, loaded microspheres were collected on day 4 for transplantation.

In order to remove empty microspheres from the preparation and prevent transfer of microspheres with minor cell content loaded carriers were manually pre-selected at day 2 under the phase contrast microscope and eGFP+ fluorescence was confirmed by fluorescent microscopy prior transplantation (Figure 1D,1E). Loaded microspheres did not display any detectable alterations in eGFP expression on day 6 and were considered as stably fluorescent. To check for cell viability an MTT test was performed and resulted in a homogenous blue staining indicative of viable cells (Figure $1 \mathrm{~F}$ ).

\section{Intra-myocardial transplantation of iPS-CM loaded microspheres}

Passing of pre-selected $\mathrm{eGFP}^{+}$microspheres through the injection cannula did not affect the integrity of the particles, indicating a sufficiently small size of the loaded spheres to pass the cannula at high density. Loaded microspheres were transplanted in $20 \mu \mathrm{l}$ cell suspension by two individual injections of $10 \mu \mathrm{l}$ into the left ventricle close to the cardiac apex. For comparison single cell suspensions of iPS-CMs were injected.

In order to validate the results hearts were harvested and genomic DNA of whole organs was isolated for Y-Chromosomes detection. As a standard for $100 \%$ cell retention additional samples were prepared 


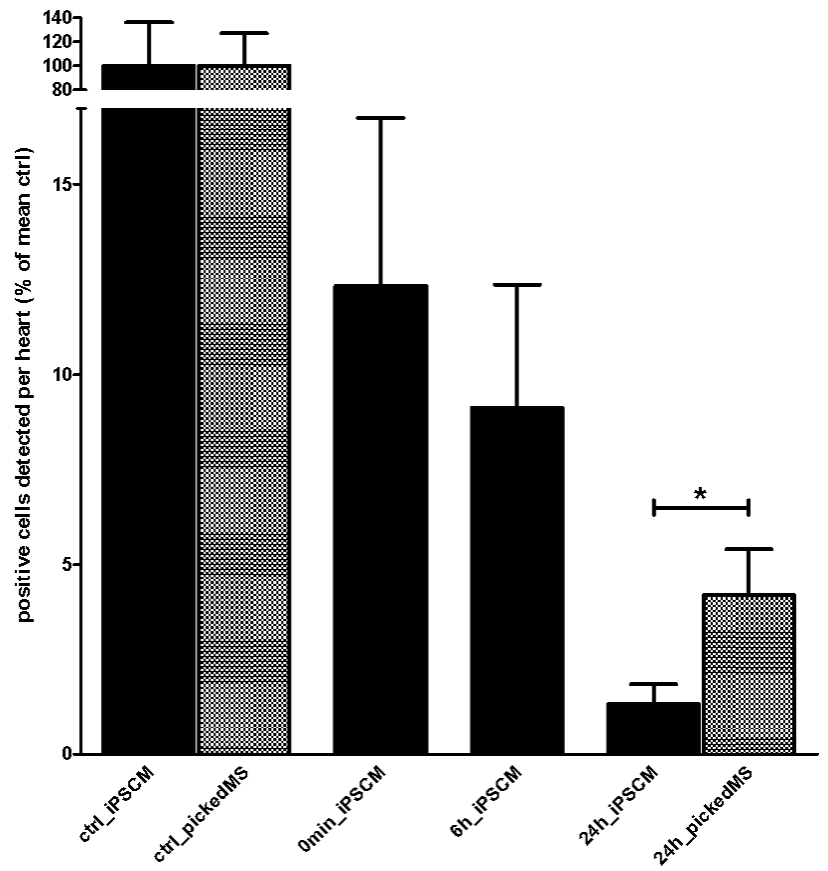

Figure 2: Transplantation of iPS cell-derived cardiomyocytes on degradable Cultisphere S microcarriers. Quantitative real time PCR data showed early cell retention in transplanted single cell suspensions of iPS-CMs at $0 \mathrm{~h}, 6 \mathrm{~h}$ and $24 \mathrm{~h}$ after transplantation. The second group validates the retention of iPSCMs cultured on microspheres. Prior to transplantation microspheres were manually selected ("picked") to excluded spheres without cell loading from the experiment. ex-vivo as control at each experimental day by application of equal cell numbers (single cells) or sphere numbers to an isolated heart ex vivo.

Real time PCR quantification (Figure 2) of transplanted single cells revealed a cell retention of $12.3 \pm 4.4 \%(\mathrm{n}=7)$ immediately after injection ("0min"), and a significant decline to $9.1 \pm 3.2 \%(\mathrm{n}=6)$ at $6 \mathrm{hrs}$ and $1.3 \pm 0.5 \%(\mathrm{n}=8)$ at $24 \mathrm{hrs}$ after injection ( $\mathrm{p}<0.05$ vs. $0 \mathrm{~min} ; \mathrm{p}<0.05$ for linear trend). Transplantation of pre-selected microspheres resulted in a cell retention of $4.2 \pm 1.2 \%(\mathrm{n}=7)$ after $24 \mathrm{hrs}$ which was significantly more than after single cell transplantation $(\mathrm{p}<0.05)$. Absolute quantification $(n=3)$ of iPS-CMs entrapped in loaded microspheres prior to transplantation revealed cell numbers of $107 \times 10^{3}, 167^{\star} 10^{3}$ and $275 \times 10^{3}$ cells per 100 microspheres.

\section{Histological analysis}

To facilitate identification of the injection site microspheres were labeled by CMTPX dye prior to cell loading (Figure 3A) while transplanted iPS-CMs were readily identified based on their eGFPexpression. Vibratome sections of $150 \mu \mathrm{m}$ thickness were prepared $24 \mathrm{hrs}$ after transplantation in order to identify tissue areas harboring transplanted microspheres. $24 \mathrm{~h}$ after transplantation, microspheres were identified in the tissue (Figure 3B,C). Vibratome sections containing transplanted microspheres were embedded for cryo-sectioning and thin section were prepared (Figure 3D-G). Red fluorescent microspheres were identified in the tissue and retained their spheroidal shape (Figure 3D,E). Green fluorescent iPS-CMs were detected in the periphery of the microspheres: Few iPS-CMs appeared to be still associated to the microspheres while most eGFP+ cells were found separated from the spheres (Figure 3E).

To track iPS-CMs long term retention further sections were prepared after 1 week (Figure $3 \mathrm{H}$ ). At this time point intact microspheres were
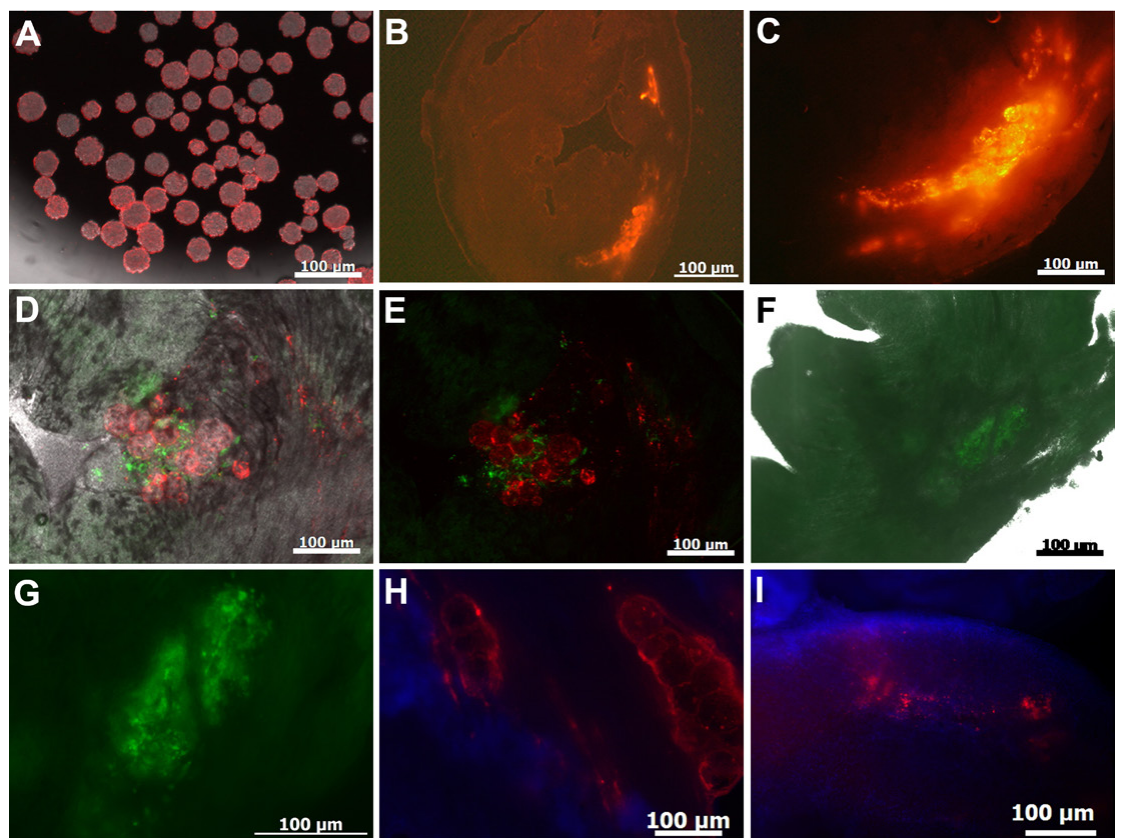

Figure 3: Histological observation of transplanted microspheres: Cultisphere S microspheres were labeled with CMTPX dye prior to cell transplantation; Images were acquired on a fluorescence microscope (A). Viable ventricular slices prepared on a vibratome indicate the presence of CMTPX labeled microsphere observed $24 \mathrm{~h}$ after transplantation into the left ventricular myocardium (B,C). Injected spheres were loaded with cardiomyocytes identified $24 \mathrm{~h}$ post transplantation showing eGFP fluorescence (iPS-CMs) and red fluorescence (CMTPX labeled microspheres) (D,E). Cryo-sections of hearts transplanted with loaded microspheres showing eGFP+ iPS-CMs 24 h post transplantation $(F, G)$. One week after transplantation microsphere was visible while eGFP+ iPS-CMs were undetectable $(H)$. After 4 weeks microspheres were degraded and no eGFP+ signals observed (I). 
Citation: Sahito RGA, Heras-Bautista CO, Krausgrill B, Maass M, Baumgartner S, et al. (2015) Gelatine Microspheres Support Direct Intramyocardial Delivery of Induced Pluripotent Stem Cell-Derived Cardiomyocytes. J Stem Cell Res Ther 5: 306. doi:10.4172/2157-7633.1000306

Page 5 of 6

identified in the tissue but iPS-CMs seemed to be absent. Finally 4 weeks after transplantation no intact microspheres were identified (Figure 3I).

\section{Discussion}

Cell persistence and cell engraftment of purified cardiomyocytes after direct intramyocardial injection is limited. Our experimental evidence suggests almost complete loss of donor cells within 24 hours after cell transplantation. Seeding of microspheres with iPSCMs immobilized the cells on the surface of the microspheres and transplantation of such constructs resulted in a 3-fold increase in iPSCMs retention $24 \mathrm{hrs}$ following cell transplantation. However, the total loss of iPS-CMs between cell transfer and the end of the first day after transplantation remained high.

Several reasons may contribute to the problem of high cell loss. The maturation stage of the transplanted cardiomyocytes could affect the integration efficiency and survival. However, the lack of terminal differentiation observed in iPS-CMs in vitro can be seen as an advantage with respect to cell transplantation because it has been demonstrated that adult rat cardiomyocytes do not engraft after transplantation while fetal and neonatal cells readily integrate into the myocardium [24]. A more recent study focuses on fetal murine cardiomyocytes and concludes that fetal cardiomyocytes of intermediate developmental age engraft more efficient that late stage fetal cardiomyocytes do [25]. We conclude that the maturation stage of the iPS-CMs is not the major reason of cell loss. It is more likely that the cells are lost already during injection. The low cell retention of $14.6 \%$ in hearts transplanted with single cell suspensions of iPS-CMs and harvested immediately after surgery supports this assumption. In order to reduce the number of experimental animals no experiments were done immediately after injection with selected microspheres, however, the comparable huge loss of iPS-CMs in the microsphere group clearly indicates that transfer of iPS-CMs bound to larger particles does not solve the issue of immediate early cell loss. Our data (Figure 3D) indicates that iPSCMs get separated from the microspheres in the tissue. This effect could be attributed to shear stresses during transfer and inside the contractile tissue as well. It would be favorable to identify microspheres that support the invasion of iPS-CMs into the surface of the carrier to protect the cells from shear stresses.

Increasing the efficiency of cardiomyocyte transplantation into the heart remains an unsolved task. Transplantation of huge cell number as demonstrated by Chong and colleagues has the potential to partially overcome the complete loss of cells and support long-term engraftment into the myocardium [11]. However, when it comes to clinical application economical considerations need to be considered and the efficiency of iPS-CMs transplantation is critical in this regard. Seeding of gelatine microcarriers did not solve the problem in the present study even though gelatine microspheres supported the culture and transfer of iPS-CMs and were shown to degrade inside the tissue within 4 weeks.

Finally, it may turn out that several roadblocks hinder the efficient transplantation of iPS-CMs and combinations of different measures need to be applied to generate a substantial effect. These measures may include: Optimized culture and preconditioning of the cells, Preparation of cell clusters or optimized cell-loaded microspheres, prevention of stress induced apoptosis, optimized injection and suture techniques, magnetic retention or bivalent antibody guided integration.

\section{Acknowledgement}

We thank Anette Peffekoven, Cornelia Böttinger, Rita Altenburg, Katja Urban and Daniel Derichsweiler for excellent technical assistance and Rouven Gotthard for support during establishment of the selection workflow for loaded microspheres.

\section{References}

1. Barad L, Schick R, Zeevi-Levin N, Itskovitz-Eldor J, Binah O (2014) Human embryonic stem cells vs human induced pluripotent stem cells for cardiac repair. Can J Cardiol 30: 1279-1287. [PubMed]

2. Fukushima S, Sawa Y, Suzuki K (2013) Choice of cell-delivery route for successful cell transplantation therapy for the heart. Future Cardiol 9: 215-227. [PubMed]

3. Cheng K, Malliaras K, Li TS, Sun B, Houde C, et al. (2012) Magnetic enhancement of cell retention, engraftment, and functional benefit after intracoronary delivery of cardiac-derived stem cells in a rat model of ischemia/ reperfusion. Cell Transplant 21: 1121-1135. [PubMed]

4. Kolossov E, Bostani T, Roell W, Breitbach M, Pillekamp F, et al. (2006) Engraftment of engineered ES cell-derived cardiomyocytes but not BM cells restores contractile function to the infarcted myocardium. J Exp Med 203: 2315-2327. [PubMed]

5. Moon SH, Ju J, Park SJ, Bae D, Chung HM4, et al. (2014) Optimizing human embryonic stem cells differentiation efficiency by screening size-tunable homogenous embryoid bodies. Biomaterials 35: 5987-5997. [PubMed]

6. Bel A, Planat-Bernard V, Saito A, Bonnevie L, Bellamy V, et al. (2010) Composite cell sheets: a further step toward safe and effective myocardial regeneration by cardiac progenitors derived from embryonic stem cells. Circulation 122 : S118-S123.

7. Furuta A, Miyoshi S, Itabashi Y, Shimizu T, Kira S, et al. (2006) Pulsatile cardiac tissue grafts using a novel three-dimensional cell sheet manipulation technique functionally integrates with the host heart, in vivo. Circ Res 98: 705-712. [PubMed]

8. Kawamura M, Miyagawa S, Miki K, Saito A, Fukushima S, et al. (2012) Feasibility, safety, and therapeutic efficacy of human induced pluripotent stem cell-derived cardiomyocyte sheets in a porcine ischemic cardiomyopathy model. Circulation 126: S29-S37.

9. Koshy ST, Ferrante TC2, Lewin SA2, Mooney DJ3 (2014) Injectable, porous and cell-responsive gelatin cryogels. Biomaterials 35: 2477-2487. [PubMed]

10. Smith RR, Marban E, Marban L (2013) Enhancing retention and efficacy of cardiosphere-derived cells administered after myocardial infarction using a hyaluronan-gelatin hydrogel. Biomatter 3. [PubMed]

11. Chong JJ, Yang X, Don CW, Minami E, Liu YW, et al. (2014) Human embryonicstem-cell-derived cardiomyocytes regenerate non-human primate hearts. Nature 510: 273-277. [PubMed]

12. Mauritz C, Schwanke K, Reppel M, Neef S, Katsirntaki K, et al. (2008) Generation of functional murine cardiac myocytes from induced pluripotent stem cells. Circulation 118: 507-517. [PubMed]

13. Pfannkuche K, Liang H, Hannes T, Xi J, Fatima A, et al. (2009) Cardiac myocytes derived from murine reprogrammed fibroblasts: intact hormona regulation, cardiac ion channel expression and development of contractility. Cell Physiol Biochem 24: 73-86.

14. Zvibel I, Smets F, Soriano H (2002) Anoikis: roadblock to cell transplantation? Cell Transplant 11: 621-630. [PubMed]

15. Robey TE, Saiget MK, Reinecke H, Murry CE (2008) Systems approaches to preventing transplanted cell death in cardiac repair. J Mol Cell Cardiol 45 567-581. [PubMed]

16. van Wezel AL (1967) Growth of cell-strains and primary cells on micro-carriers in homogeneous culture. Nature 216: 64-65. [PubMed]

17. Uusimaa PA, Hiltunen JK, Sormunen RT, Hassinen IE (1988) Microcarrier culture of neonatal cardiac myocytes in metabolic studies. Cardiovasc Res 22 291-295. [PubMed]

18. Lecina M, Ting S, Choo A, Reuveny S, Oh S (2010) Scalable platform for human embryonic stem cell differentiation to cardiomyocytes in suspended microcarrier cultures. Tissue Eng Part C Methods 16: 1609-1619. [PubMed]

19. Ting S, Chen A, Reuveny S, Oh S (2014) An intermittent rocking platform for integrated expansion and differentiation of human pluripotent stem cells to cardiomyocytes in suspended microcarrier cultures. Stem Cell Res 13: 202213. [PubMed]

20. Potta SP, Sheng X, Gaspar JA, Meganathan K, Jagtap S, et al. (2012) Functiona characterization and gene expression profiling of alpha-smooth muscle actin expressing cardiomyocytes derived from murine induced pluripotent stem cells. Stem Cell Rev 8: 229-242. 
Citation: Sahito RGA, Heras-Bautista CO, Krausgrill B, Maass M, Baumgartner S, et al. (2015) Gelatine Microspheres Support Direct Intramyocardial Delivery of Induced Pluripotent Stem Cell-Derived Cardiomyocytes. J Stem Cell Res Ther 5: 306. doi:10.4172/2157-7633.1000306

21. Halbach M, Pfannkuche K, Pillekamp F, Ziomka A, Hannes T, et al. (2007) Electrophysiological maturation and integration of murine fetal cardiomyocytes after transplantation. Circ Res 101: 484-492. [PubMed]

22. Müller-Ehmsen J, Peterson KL, Kedes L, Whittaker P, Dow JS, et al. (2002) Rebuilding a damaged heart: long-term survival of transplanted neonatal rat cardiomyocytes after myocardial infarction and effect on cardiac function. Circulation 105: 1720-1726. [PubMed]

23. Krausgrill B, Vantler M, Burst V, Raths M, Halbach M, et al. (2009) Influence of cell treatment with PDGF-BB and reperfusion on cardiac persistence of mononuclear and mesenchymal bone marrow cells after transplantation into acute myocardial infarction in rats. Cell Transplant 18: 847-853.

24. Reinecke H, Zhang M, Bartosek T, Murry CE (1999) Survival, integration, and differentiation of cardiomyocyte grafts: a study in normal and injured rat hearts. Circulation 100: 193-202. [PubMed]

25. Halbach M, Baumgartner S, Sahito RG, Krausgrill B, Maass M, et al. (2014) Cell persistence and electrical integration of transplanted fetal cardiomyocytes from different developmental stages. Int J Cardiol 171: e122-124. [PubMed] 